\title{
Evaluation of Ability to Supply Water Based on GRNN Neural Network Model: Case of Beijing
}

\author{
Jiaming Tian \\ Department of Power Engineering, North China Electric Power University, Baoding, Hebei 071003, \\ PR China \\ 992460456@qq.com
}

Keywords: Evaluating system; Ability to supply water; AHP; GRNN neural network.

\begin{abstract}
Water supply capacity is an important index for evaluating a city. In this paper, AHP (Analytic Hierarchy Process) is used to establish an index system and evaluation standard of the ability to supply water, and 15 evaluation indicators are put forward from 4 aspects of the relationship of supply and demand, the geographical factors, the economic factors and the environmental factors. Evaluation model for ability to supply water is established by the principle of GRNN (General Regression Neural Network) theory and methods. And then the model is used to comprehensively evaluate the water supply capacity of Beijing in 2005-2015, which is proved that the established GRNN evaluation model and evaluation method are reasonable and feasible.
\end{abstract}

\section{Introduction}

Water is vital for all kinds of life living in the earth. The human body, myriad ecological system and the big biosphere of our entire planet, all of these can't live without sufficient water. However, the shortage of water resources is the main obstacle for the development of many regions and countries.

Due to the water resources evaluation system is complex and the evaluation index is numerous, simple selection and weighting have obvious subjective components [1].

In order to provide an objective assessment of water supply capacity, this paper establishes the evaluating indicator system of the ability to supply water which consists of the target layer, the principle layer and the indicator layer. GRNN algorithm is used to find the corresponding relationship between principle layer and indicator layer. Using the value of 15 indicators, the model can get a city's capacity to supply water.

\section{Water Supply Capacity Evaluation Model}

\subsection{The Selection of Principles and Indicators Based on AHP}

Based on the existing water resources evaluation index, this paper applies the analytic hierarchy process component to the index system of water resources development and utilization in Beijing.

We divide the evaluating system into three layers. The first layer is our target layer, setting up comprehensive index to evaluate ability to supply water which is computed by the principle layer. Next is the principle layer and we set four indexes consisting of the supply and demand of water, the geographic factor, the economic factors and the environmental factors. Finally, the third layer consists of detailed indicators of four principle layers.

In order to measure accurately ability to supply water, this paper puts forward standard values, as is shown on the Table 1, corresponding to different levels based on the following principles [2]:

Refer or analogy to standard values corresponding to different levels according to relevant references

Adopt existing national or international standard values.

The standard values should be consistent with the plan of national and local water resource development. 
Table 1 The different level and its corresponding specific standard values

\begin{tabular}{|c|c|c|c|c|c|c|c|c|}
\hline \multirow{2}{*}{$\begin{array}{l}\text { The target } \\
\text { layer }\end{array}$} & \multirow{2}{*}{ The principle layer } & \multicolumn{7}{|c|}{ The indicator layer } \\
\hline & & Indicator & 1 & 2 & 3 & 4 & 5 & range \\
\hline \multirow{15}{*}{$\begin{array}{l}\text { Ability to } \\
\text { water supply }\end{array}$} & $\begin{array}{l}\text { The relationship of supply } \\
\text { and demand }\end{array}$ & $\begin{array}{c}\text { The relationship of supply and } \\
\text { demand }\end{array}$ & $\geq 1.5$ & $\geq 1.3$ & $\geq 1$ & $\geq 0.5$ & $<0.5$ & $0.1 \sim 2$ \\
\hline & \multirow{3}{*}{ The geographical factors } & The amount of precipitation & $\geq 1500$ & $\geq 1200$ & $\geq 1000$ & $\geq 800$ & $<800$ & $400 \sim 3000$ \\
\hline & & $\begin{array}{l}\text { The proportion of } \\
\text { surface water and groundwater }\end{array}$ & $\geq 90$ & $\geq 85$ & $\geq 75$ & $\geq 60$ & $<60$ & $20 \sim 100$ \\
\hline & & The density of water resource & $\geq 80$ & $\geq 60$ & $\geq 40$ & $\geq 20$ & $<20$ & $10 \sim 160$ \\
\hline & \multirow{5}{*}{ The economic factors } & The proportion of external water & $\geq 20$ & $\geq 10$ & $\geq 6$ & $\geq 2$ & $<2$ & $0 \sim 30$ \\
\hline & & $\begin{array}{l}\text { The water demand quota of } \\
\text { agricultural irrigation }\end{array}$ & $\geq 2000$ & $\geq 1500$ & $\geq 1000$ & $\geq 500$ & $<500$ & $100 \sim 3000$ \\
\hline & & $\begin{array}{c}\text { The water demand of a unit industrial } \\
\text { added value }\end{array}$ & $\leq 30$ & $\leq 50$ & $\leq 100$ & $\leq 200$ & $>200$ & $10 \sim 300$ \\
\hline & & The proportion of recycled water & $\leq 3000$ & $\leq 4500$ & $\leq 6000$ & $\leq 7500$ & $\stackrel{>}{>}$ & $1500 \sim 10000$ \\
\hline & & The processing ratio of sewage & $\leq 10$ & $\leq 40$ & $\leq 55$ & $\leq 70$ & $>70$ & $5 \sim 100$ \\
\hline & \multirow{6}{*}{ The environmental factors } & The per capita water resources & $\geq 40$ & $\geq 30$ & $\geq 20$ & $\geq 10$ & $<10$ & $2 \sim 50$ \\
\hline & & The water demand of a unit GDP & $\geq 90$ & $\geq 80$ & $\geq 40$ & $\geq 20$ & $<20$ & $0 \sim 100$ \\
\hline & & $\begin{array}{l}\text { The proportion of water demand for } \\
\text { environmental protection }\end{array}$ & $\leq 10$ & $\leq 15$ & $\leq 25$ & $\leq 30$ & $>30$ & $6 \sim 100$ \\
\hline & & The qualification rate of aquifer & $\leq 5$ & $\leq 10$ & $\leq 20$ & $\leq 25$ & $>25$ & $1 \sim 30$ \\
\hline & & $\begin{array}{l}\text { The per capita amount of sewage } \\
\text { produced }\end{array}$ & $\geq 45$ & $\geq 30$ & $\geq 20$ & $\geq 10$ & $<10$ & $5 \sim 50$ \\
\hline & & The sewage produced of a unit GDP & $\geq 90$ & $\geq 75$ & $\geq 60$ & $\geq 40$ & $<40$ & $20 \sim 100$ \\
\hline
\end{tabular}

In order to evaluate the ability to supply water, there are 5 levels. For example, if the value of evaluating result is between 1 and 2, the level is best. From 1 to 5 , the situation gets worse successively.

\subsection{Model Implementation Based on GRNN}

\subsubsection{The Analysis of GRNN Model}

The GRNN neural network consists of four layers, including the input layer, the model layer, the summation layer and the output layer.

The input layer

Firstly, we normalize all data in the Table 1, which is the input data. The input layer directly passes the input variables of 15 indicators to the mode layer. The number of neurons in this layer is the dimension of input vector. A 100 by 15 input matrix can be constructed according to the number of input vectors is 100 and the number of input vectors is 15 .

The Model layer

The number of neuron in the model layer is the number of learning samples. Each neuron corresponds to its own sample, which is the transfer function of neuron in this layer can be represented as:

$$
p_{i}=\exp \left[-\frac{\left(X-X_{i}\right)^{T}\left(X-X_{i}\right)}{2 \sigma^{2}}\right] \quad i=1,2, \cdots 15
$$

Where $\mathrm{x}$ is the input variables in the network, 15 is the number of the indicators. $X_{i}$ is the learning sample of the ith neuron. $\sigma$ is the smoothing factor.

The summation layer

This layer calculates the sum of two types of neurons using arithmetic summation and weighted summation respectively.

The result of arithmetic summation $\left(S_{D}\right)$ is the sum of the output of all neurons $\left(P_{i}\right)$ in the model layer. The formula can be shown as: 


$$
S_{D}=\sum_{i=1}^{4} P_{i}
$$

The result of weighted summation $\left(S_{N j}\right)$ is the sum of all products of the output of all neurons $\left(P_{i}\right)$ in the model layer and its corresponding weights $\left(y_{i j}\right)$

$$
S_{N j}=\sum y_{i j} p_{i} \quad j=1
$$

The output layer

The output of the network is the level of the economic factors. The number of neurons in the output layer is the dimension of the output vector in the learning sample. The output neuron(Y) is our evaluating result which can be shown as:

$$
Y=\frac{S_{N j}}{S_{D}} \quad j=1
$$

\subsubsection{The Training and Test of GRNN Network}

First, we divide the 100 sets of data into two parts. The first 80 groups were trained as network, and the remaining 20 groups were used to test the quality of network's training.

Both learning speed and value of mean square error will directly affect the accuracy of network training. Through many attempts, we set learning speed and the maximum value of mean square error as 0.1 and 20 , respectively.

As is shown by the results, the data resulting from network's training is great when the value of network's training is 0.1 . The smaller the value of learning speed, the smaller the deviation between samples and network is.

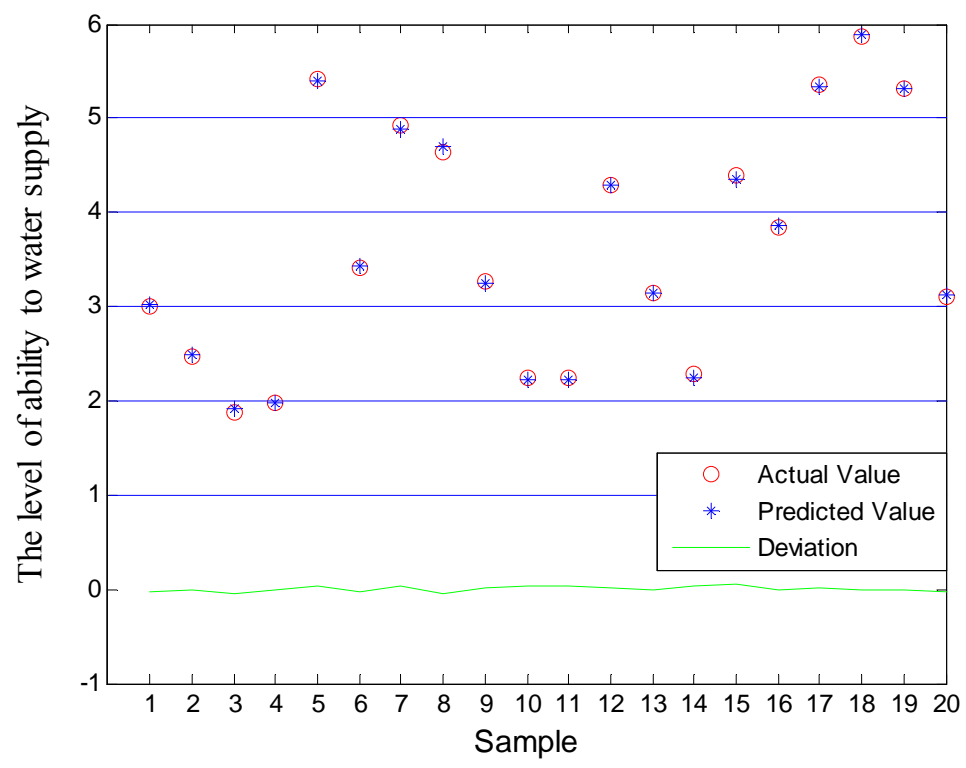

Fig. 1 The test of the network's training

As is shown on Fig.1, 20 points represent 20 sets of data. The circle represents the actual value, and the asterisk represents the predicted value. From here we can see the level of water supply for each sample. At the same time, the green curve in the Figure 1 represents the deviation between actual value and predicted value of predicted value. The smaller the deviation is, the more robust the network is.

\section{Beijing Case Study}

Based on the values of parameters of Beijing from 2005 to 2015 according to relevant reference [3], we calculate the level of four principle layers, as is shown on Fig 2. At the same time, we get the evaluating results of the ability to water supply, as is shown on Fig 3. 


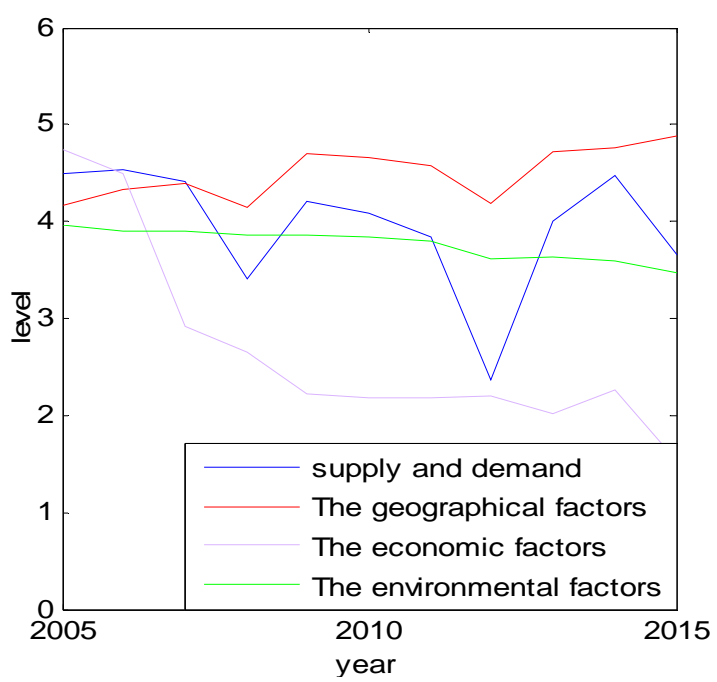

Fig 2 The evaluating results of four principle layers

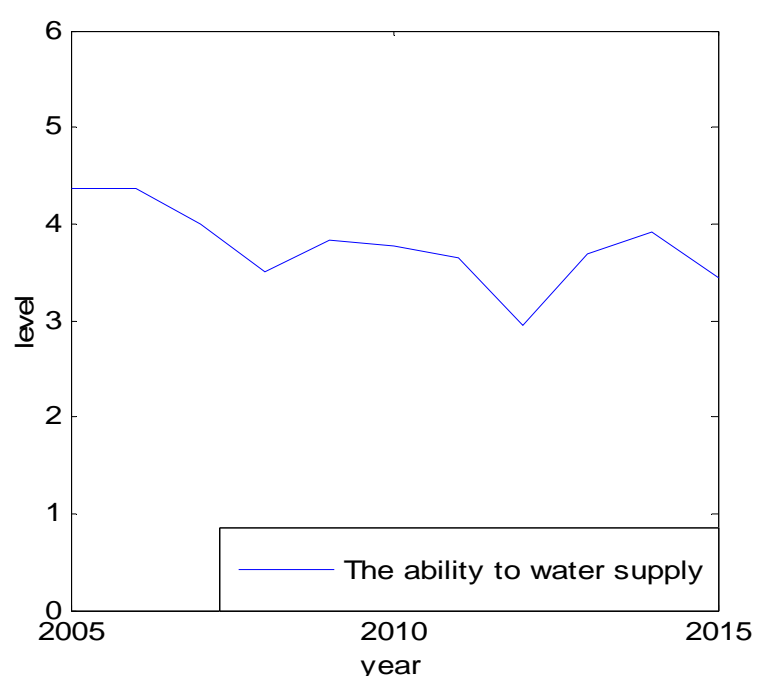

Fig 3 The evaluating results of the ability to water supply

According to relevant references, our evaluating results are consistent with objective facts.

In the past ten years, the situation of Beijing's geographical environment has increasingly become worse, which is the main factor affecting the water supply. On the contrary, economic factors have risen rapidly, reaching the highest level in 2015. It mainly resulted in the rapid development of water-saving technologies. The level of relationship between supply and demand has fluctuated significantly in 2008 and 2012, mainly due to the sudden increase in precipitation over the past two years. However, the remaining years are still worrying. Environmental factors gradually improve, but the speed of improvement is relatively slow because of the large base of population in Beijing.

\section{Conclusion}

This model is more objective in the selection of indicators. And the status of water resources in Beijing can be easily seen through the rank evaluation. Through the long-term simulation results in Beijing, it is proved that the established GRNN evaluation model and evaluation method are reasonable and feasible.

GRNN network evaluation model has the characteristics of fast convergence, high prediction accuracy, less parameters adjusting, uneasy to fall into local minimums, and can predict and evaluate more quickly to meet the objective evaluation requirements of the ability to supply water.

\section{References}

[1]. J.1. Gong. "The analysis about the trend of Dalian Water Supply and Demand," Liaoning normal University, dalian, china. Jun. 2010.

[2]. CUI Dong-wen1, GUO Rong2, "Evaluation of sustainable utilization of regional water resources based on GRNN neural network model: case of Wenshan Prefecture of Yunnan Province," Yangtze River, vol.43, no.5, pp.26-31, 2012.

[3]. "Beijing implements river lake ecological environment management "river system."." Beijing water authority .6th Jun 2016.

http://www.bjwater.gov.cn/bjwater/300747/300754/300761/szfgfxwj/306836/index.html 